\title{
A Robust Virtual Inertia Control of Battery Storage System to Enhance Transient Stability of Grid System including Wind Farms
}

\author{
Rima Sultana, Md. Rifat Hazari, Mohammad Abdul Mannan and Junji Tamura
}

\begin{abstract}
With the rising penetration of modern converter-based wind farm (WF) into the existing grid system deteriorates system inertia due to reduction of the capacity of conventional power stations which may lead to the frequency instability as well as power system transient instability. In order to solve this concern, this paper presents a robust virtual inertia control approach for battery storage system (BSS) to enhance the frequency stability of the grid system after the generation failure owing to severe grid disruption. The control approach integrated inertial controller based on the rate of change of frequency (ROCOF) and droop controller according to frequency deviation. The impacts of the proposed virtual inertia controller (VIC) is confirmed through simulation analysis on a multi-machine power system with conventional power stations, permanent magnet synchronous generator (PMSG) with full converter based WF and squirrel cage induction generator (SCIG) based WF. Simulation study clearly demonstrates that by adopting both strategies, the BSS can effectively minimize the frequency nadir and steady-state error.
\end{abstract}

Keywords: Frequency stability, battery storage system, PMSG, SCIG, power system, virtual inertia.

\section{Introduction}

Over the past few decades, the world's electricity needs are increasing significantly. Many countries are installing renewable energy sources (RESs) to meet this demand [1-2]. RESs have several merits over conventional power stations, such as: less $\mathrm{CO}_{2}$ emission, cost effectiveness, sustainability, environmentally friendly etc. [3].

Between a variety of renewable energy sources, wind power (WP) is the most auspicious source for the production of electricity with least environmental impact [4]. The global new WP installed capacity was $60 \mathrm{GW}$ in 2019 which was about $19 \%$ growth compared to 2018 [5]. The total installed capacity of WP is $650 \mathrm{GW}$ at the end of 2019 [5].

Rima Sultana is a master's student of EEE department of American International University-Bangladesh, Dhaka-1229, Bangladesh. Email: rimaahona5@gmail.com

Md. Rifat Hazari is an Assistant Professor of the Department of EEE, American International University-Bangladesh, 408/1, Kuratoli, Khilkhet, Dhaka-1229, Bangladesh. Email: rifat@aiub.edu Mohammad Abdul Mannan is a Professor and Director of the Department of EEE, American International University-Bangladesh, 408/1, Kuratoli, Khilkhet, Dhaka-1229, Bangladesh. Email: mdmannan@aiub.edu

Junji Tamura is a Professor at EEE Dept. of Kitami Institute Technology, 165 Keon-cho, Kitami, Hokkaido, 090-8507, Japan. Email: tamuraj@mail.kitami-it.ac.jp
Market intelligence of the global wind energy council (GWEC) anticipates that over $355 \mathrm{GW}$ of new capacity will be added [5]. That is approximately 71 GW of new installations to each year until 2024 [5].

Now a days, wind turbines based on PMSG is an extremely prevalent choice to install new WF due to several merits, for example: variable speed operation, separate control of active and reactive power, no gearbox and brush are required and low maintenance [6-7]. However, integration of the large-scale PMSG based WFs into the power system declines the reliance on conventional units and introduces frequency stability issues because of low inertia of the grid system [8], which incorporates the following points [3, 9-10]:

(1) PMSG shows no inertial responses which may cause of frequency instability.

(2) The frequency of the power system fluctuates from the rated value during any generation outage due to fault condition or any sudden load change.

(3) The ROCOF and frequency nadir are higher in case of generation outage/sudden load change, which may trigger the controller of load shedding to trip frequency relay.

Many researchers have developed VIC integrated with maximum power point tracking (MPPT) algorithm of PMSG to emulate inertial response similar like conventional synchronous generators (SGs) [11-16]. For example, droop control [11], ROCOF control [12], and ROCOF and droop control [13-16]. Even though, the above strategies may prevent the frequency dip by injecting stored kinetic energy (KE) into the rotor terminal in the form of inertial response, but the $\mathrm{KE}$ extraction completely depends upon the wind speed and it cannot ensure frequency stability during low wind speed situations [17-18]. Also, some researchers proposed some approaches to utilize the electrostatic stored energy in the DC-Link capacitor of variable speed wind turbine (VSWT) with PMSG to offer virtual inertia support [19-21]. However, the available DCLink capacitor energy is somewhat small which limits the frequency stabilization.

Considering the above concerns, this paper solves the frequency stability issues by employing BSS. The main contributions of this study are as follows:

(1) An appropriate VIC control technique of BSS is designed in order to augment the frequency stability. The proposed frequency dependent VIC of BSS is composed of both droop loop and ROCOF loop to ensure effective amount of active power injection 


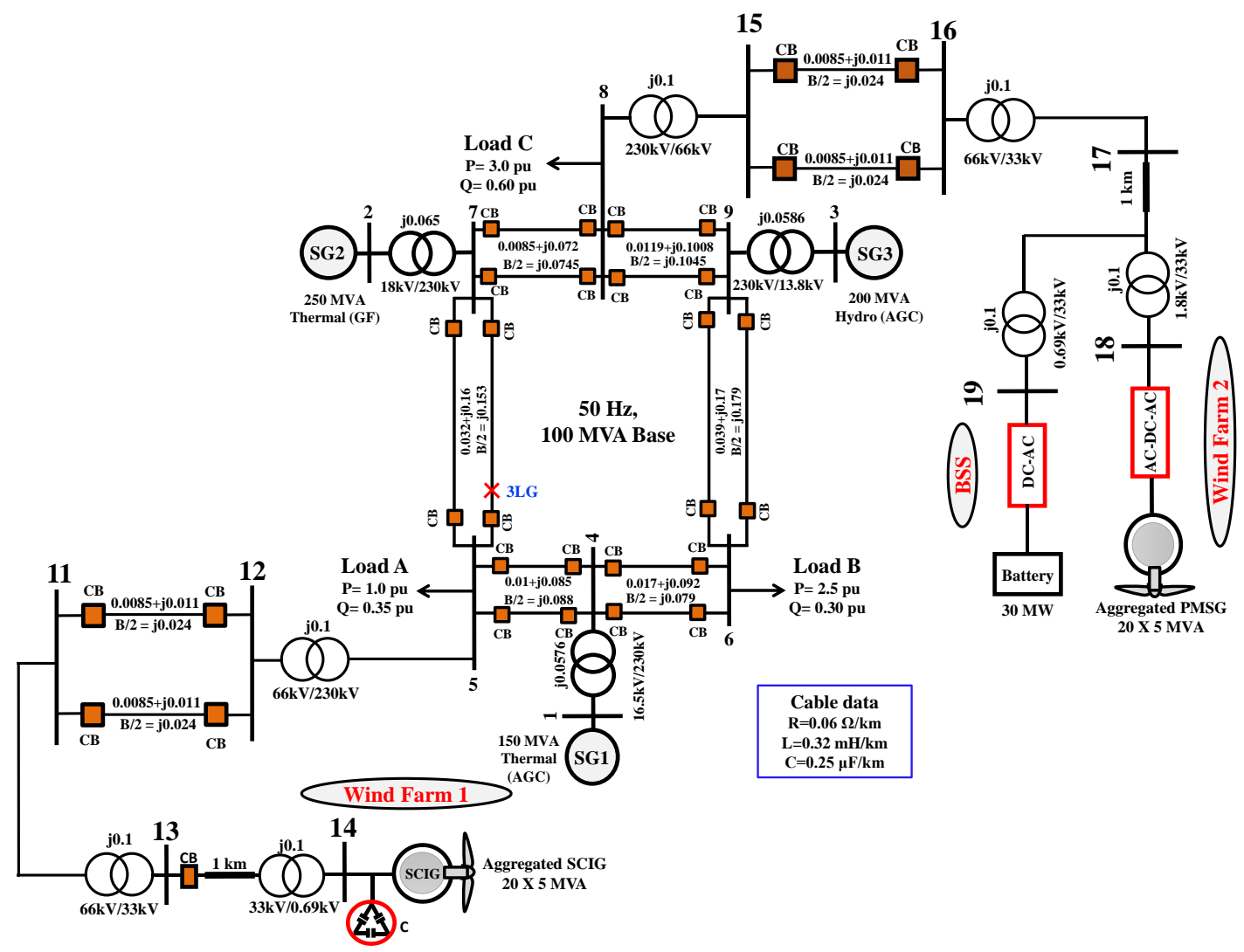

Fig. 1: System model.

during transient period. This is the salient feature of this work.

(2) The robust performance of the designed VIC controlled BSS system is investigated through simulation assessments on a multi-machine IEEE ninebus system model composed of SCIG, PMSG and conventional SGs during outage of WF consists of fixed speed wind turbine (FSWT) with SCIG due to serious network fault. Simulations are performed by using the PSCAD/EMTDC software.

(3) This paper also describes the detail explanations of wind turbine model, IEEE nine-bus power system model, PMSG system along with its control strategy as well as proposed VIC controlled BSS system.

The remainder of the paper is arranged as follows: Section 2 discusses the system model; Section 3 and 4 explains the mechanical modeling of the wind turbine and PMSG system. Section 5 shows the BSS system with proposed VIC. The simulation analysis and discussions are given in Section 6 and at last section 7 concludes the paper.

\section{System Model}

The test power system model applied in this study is demonstrated in Fig. 1. Two different kinds of WFs are connected to Bus 5 and Bus 8 of the standard IEEE nine-bus system through $1 \mathrm{~km}$ cables, transmission lines and transformers, respectively. The capacities of WF1 and WF2 are identical, which is $100 \mathrm{MW}$ each. The WF1 is composed of twenty FSWT-SCIG and each has a rating of $5 \mathrm{MW}$. The capacitor bank near the terminal of the SCIG is used to provide reactive power. The WF2 is also composed of twenty VSWT-PMSG with $5 \mathrm{MW}$ capacity of each turbine. The full frequency converter is also utilized to connect the PMSG with the grid system. Finally, a BSS is linked to the PMSG system with the assistance of inverter and transformer for supporting the additional active power in the form of inertial response and its capacity is $30 \mathrm{MW}$.

The nine-bus system used one hydro power plant and two thermal power plants. Automatic generation control (AGC) technique is adopted in SG1 and SG3 whereas governor-free (GF) control technique is considered for SG2. All the necessary parameters of WFs, SGs, exciter model as well as thermal and hydro turbine models are carried from Refs. [7, 17, 22].

\section{Mechanical Modeling of Wind Turbine}

The three bladed horizontal axis wind turbine is the most popular choice for high capacity wind power production. The power captured by the wind turbine $\left(P_{W}\right)$ is mainly relies upon the wind speed $\left(V_{w}\right)$, air density $(\rho)$, blade radius $(R)$ and power co-efficient $(C p)$ as presented in equation (1). The $C p$ is a function of tip speed ratio $(\lambda)$ and pitch angle of the blade $(\beta)$ [23].

$$
P_{w}=0.5 \rho \pi R^{2} V_{w}^{3} C_{p}(\lambda, \beta)
$$

The equation of $C p$ can be expressed as below [23]: 
$C_{p}(\lambda, \beta)=c_{1}\left(\frac{c_{2}}{\lambda_{i}}-c_{3} \beta-c_{4}\right) e^{\frac{-c_{5}}{\lambda_{i}}}+c_{6} \lambda$

$\frac{1}{\lambda_{i}}=\frac{1}{\lambda-0.08 \beta}-\frac{0.035}{\beta^{3}+1}$

Finally, the $\lambda$ can be calculated using equation (4), which depends upon turbine rotor speed $\left(\omega_{r}\right), R$ and $V_{w}$ [23]:

$$
\lambda=\frac{\omega_{r} R}{V_{w}}
$$

The $C_{p}-\lambda$ curve demonstrated in Fig. 2 is computed by applying equation (2), where the optimum $C_{p}$ $\left(C_{p \_o p t}\right)=0.48$ and optimum $\lambda(\lambda o p t)=8.1$. These optimum values are considered for designing the MPPT power $\left(P_{M P P T}\right)$ algorithm as presented in equation (5) [6]:

$$
P_{M P P T}=0.5 \rho \pi R^{2}\left(\omega_{r} R / \lambda_{\text {opt }}\right)^{3} C_{p_{-} \text {opt }}
$$

The MPPT algorithm is demonstrated in Fig. 3. The pitch angle controllers employed in SCIG and PMSG systems are presented in Fig. 4, which are used to ensure smooth operation beyond rated wind speed [6, 23].

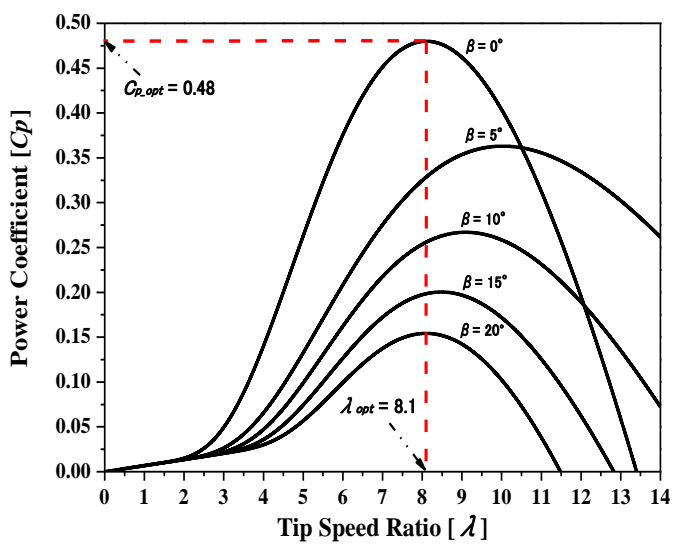

Fig. 2: Curve of $C_{p}-\lambda$.

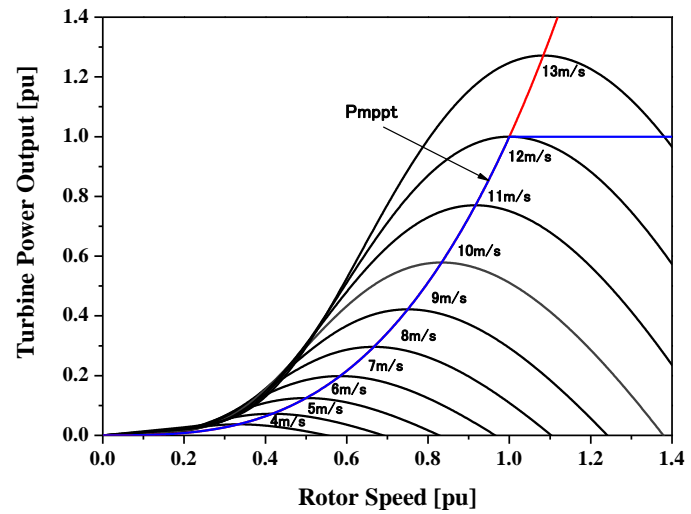

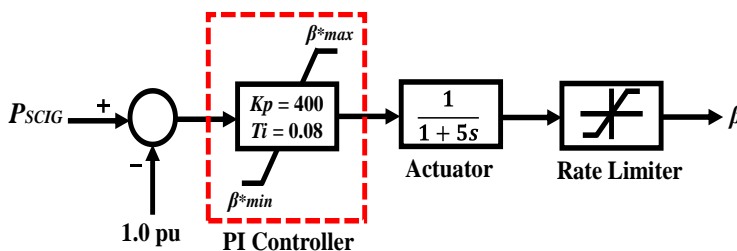

(a) SCIG

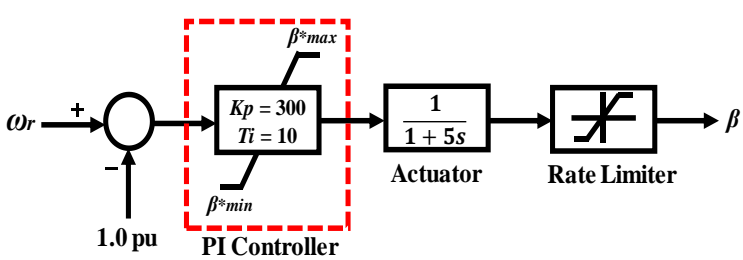

(b) PMSG

Fig. 4: Controller of pitch angle.

\section{Design of PMSG System and Cascaded Control Strategies}

The overall structure of the PMSG system and detail control strategies are demonstrated in Fig. 5. The variable low speed wind turbine is directly attached to the PMSG system without any gearbox. As a result, variable low frequency output is generated in the generator system. This low frequency electrical power is transmitted to the grid system using full rating two level back to back (BtB) frequency converter as presented in Fig. 5.

The BtB frequency converter composed of machine side converter (MSC) and grid side converter (GSC). Two level converter technology is based on six insulated gate bipolar transistors (IGBTs) and antiparallel diodes. The MSC is acts as rectifier whereas GSC as inverter. A DC chopper is also attached with the PMSG system to protect the PMSG system during fault condition [7].

To control the MSC, a cascaded machine side control strategy consists of outer and inner loops are used. The outer loop extracts the MPPT power from the wind turbine system and regulates the reactive power to zero for the operation of unity power factor. The inner loop adjusts the $\mathrm{d}$-axis and $\mathrm{q}$-axis stator current. The angle of transformation $\left(\theta_{e}\right)$ is obtained from the rotor position of generator.

The GSC is controlled by the grid side controller as demonstrated in Fig. 5. In the outer loop, the q-axis grid current $\left(I_{g q}\right)$ is related to DC-Link voltage $\left(V_{d c}\right)$ and daxis grid current $\left(I_{g d}\right)$ is related to reactive power of the grid system. The reference $I_{g d}$ and $I_{g q}\left(I_{g d} *\right.$ and $\left.I_{g q} *\right)$ are obtained by regulating the grid side reactive power $\left(Q_{\mathrm{g}}\right)$ to zero and $V_{d c}$ with pre-defined reference $V_{d c}(3 \mathrm{kV})$.

The well-known PI controllers are applied for both outer and inner loops of machine side and grid side controller to generate reference signals.

Finally, this reference signals are compared with pulse width modulation (PWM) technique to produce gate signals of MSC and GSC, respectively.

Fig. 3: MPPT curve of PMSG. 


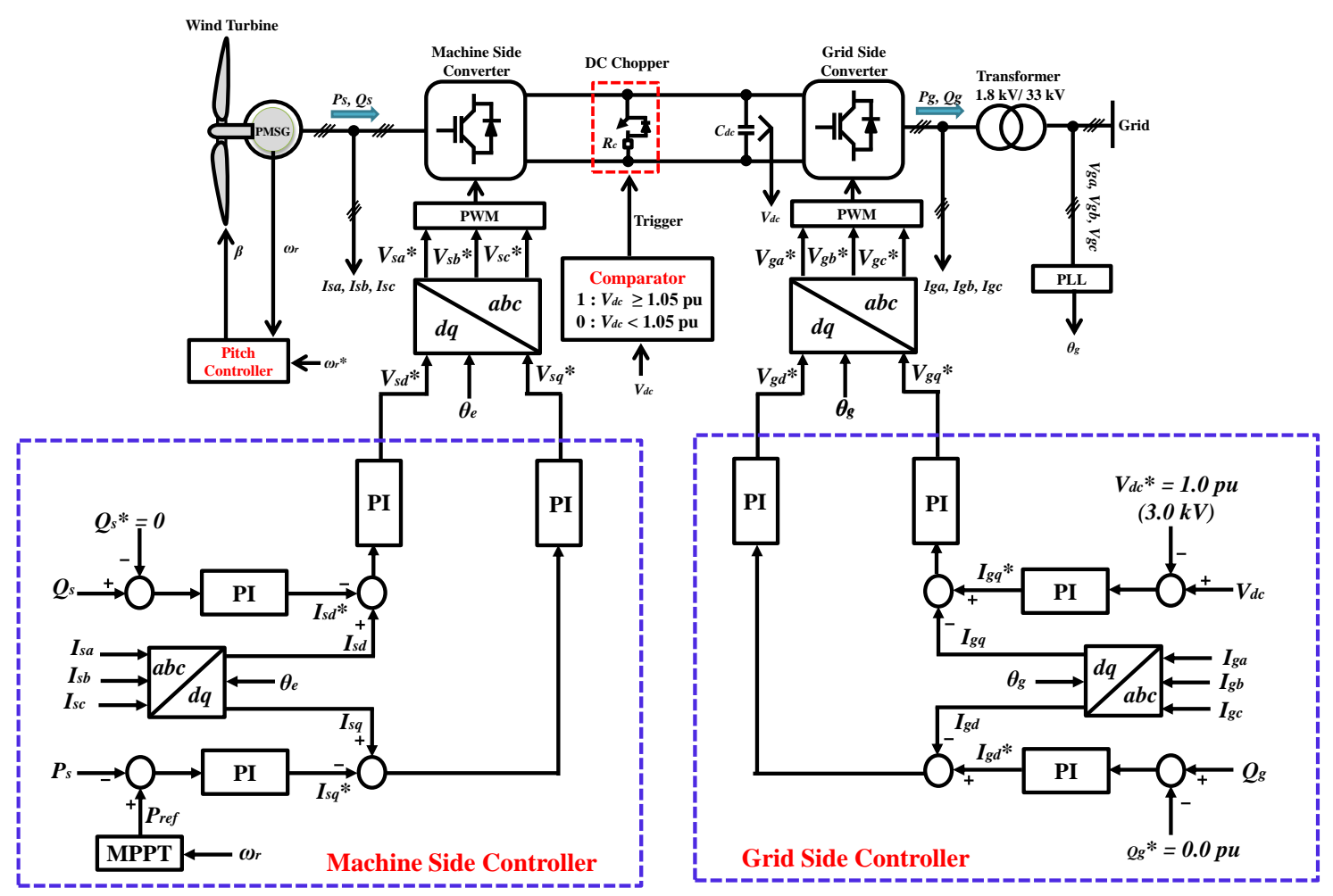

Fig. 5: Grid-tied PMSG model with cascaded control strategies.
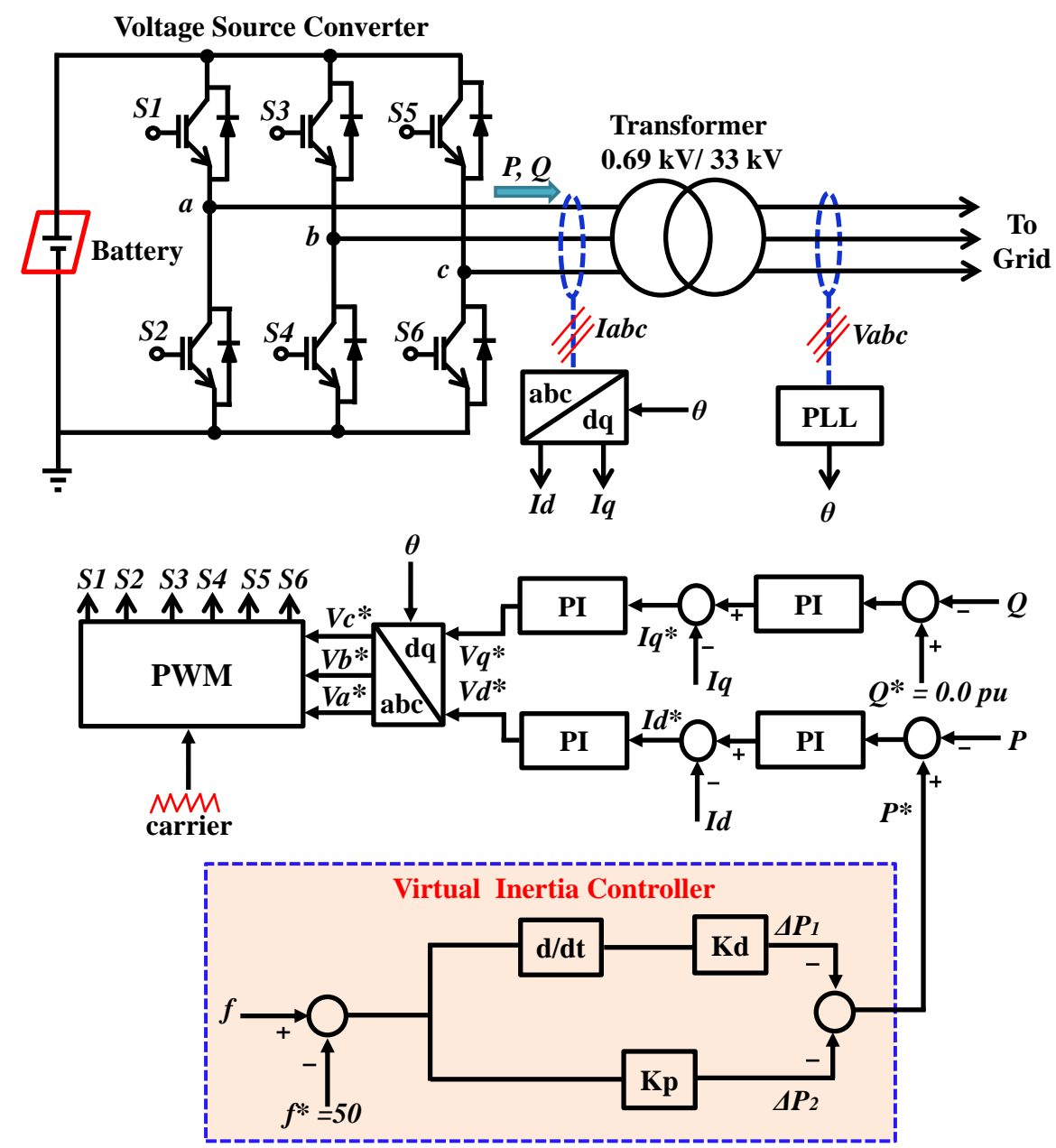

Fig. 6: Grid-tied BSS model with proposed VIC. 


\section{Design of BSS and Proposed VIC}

The main structure of the BSS and its detail control strategy including proposed VIC is demonstrated in Fig. 6. The BSS system is consisting of a standard leadacid battery unit which is represented by constant voltage source for simplicity, a two-level voltage source converter and a transformer. The VSC will serve the purpose of converting the DC voltage of the battery unit to the grid synchronized AC voltage. The control strategy of the battery is also depicted in the same diagram. Cascaded control strategy based on four wellknown PI controllers is employed. The PI controllers will compensate different error signals. In the upper loop, the reactive power $(Q)$ of the output of inverter system is considered as input signal. The reactive power reference $\left(Q^{*}\right)$ is set as zero to guarantee the operation of the unity power factor. This error signal will be processed by the PI controller to generate the qaxis reference current $\left(I_{q} *\right)$. The lower loop of the cascaded control strategy is basically the unique feature of this work which adopted inertial control strategy. It takes the frequency $(f)$ of the grid system as input signal. This VIC will generate necessary active power reference $\left(P^{*}\right)$ to operate the battery during frequency instability event. To perform effective inertial control, it is composed of ROCOF loop as well as droop loop as shown in the below equations:

$$
\begin{aligned}
& \Delta P_{1}=K d \frac{d}{d t} \Delta f \\
& \Delta P_{2}=K p \Delta f
\end{aligned}
$$

Where, $\Delta f$ is the frequency deviation with respect to the base system frequency, $K p$ and $K d$ are fixed gains.

According to equation (6), when the frequency declines after a trip of a generation unit, the $P^{*}$ will increase based upon the value of $\Delta f$ and $K d$. Thus, it can effectively arrest the frequency nadir by adding supplementary amount of active power from the BSS. Moreover, a droop loop $\left(\Delta P_{2}\right)$ proportional to the $\Delta f$ is also inserted in the VIC strategy as presented in equation (7). It is used to minimize the frequency deviation at steady-state period by increasing the BSS output power. Finally, this $P^{*}$ is compared with the actual active power $(P)$ of the BSS to generate error signal. After that, this error signal will be processed by the PI controller to generate reference d-axis $\left(I_{d} *\right)$ current.

In this way, the BSS can effectively contribute during frequency instability event by incorporating both droop loop and ROCOF loop.

\section{Simulation Analysis and Discussion}

Simulation study is conducted on the same system model of Fig. 1 to confirm the significance of the proposed VIC controlled BSS. In the main system, three line to ground (3LG) is carried as severe network disruption. The fault conditions are: fault occurred at $0.1 \mathrm{~s}$, duration of fault is $0.1 \mathrm{~s}$, circuit breakers (CBs) opened at 0.2 and CBs closed at $1.0 \mathrm{~s}$. Also, the wind speed incoming to the PSMG and SCIG are assumed constant at rated condition. Because the wind speed acts almost constant within a small period. Two cases have been analyzed in this work, where no BSS is employed in the PMSG system in Case 1 and proposed BSS system is employed in the PMSG system in Case 2.

Fig. 7 demonstrates the terminal voltage profile of SCIG for both cases. The terminal voltage is failed to reach its pre-fault value after 3LG fault, thus the SCIG system is disconnected from the main power system of Fig. 1 at $\mathrm{t}=2.0 \mathrm{~s}$ by following the standard fault ride though (FRT) grid code [24]. Due to this disconnection, the active power profile of SCIG is zero after $2.0 \mathrm{~s}$ as depicted in Fig. 8. This shortage of active power enables the conventional SGs to respond the load demand. Thus, the SGs are supplying extra active power in Case 1 in the form of KE as shown in Fig. 9. Thus, the power system frequency and rotor speed profiles of SGs are more fluctuating more in Case 1 as demonstrated in Figs. 10 and 11. On the contrary, the BSS is providing active power after the fault based on the frequency deviation in Case 2 as shown in Fig. 12. Now, the frequency and rotor speeds of SGs are less fluctuating during transient period in Case 2 with respect to Case 1 . Because the BSS system is equipped with proposed VIC as discussed in Section 5.

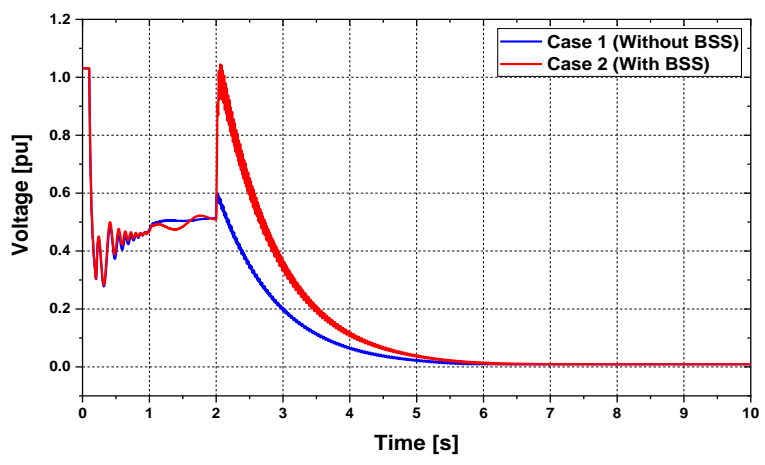

Fig. 7: Terminal voltage profile of SCIG.

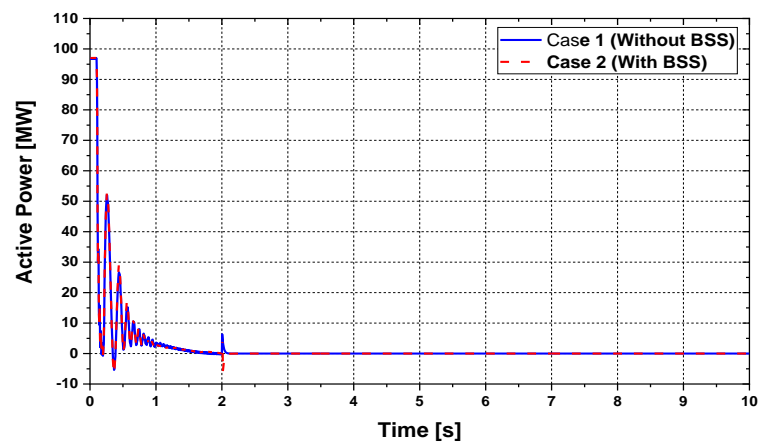

Fig. 8: Active power profile of SCIG.

The active power of PMSG system is recovered little bit quicker to the nominal value in Case 2 than in Case 1 as shown in Fig. 13. Fig. 14 shows the rotor speed profile of PMSG and it is less fluctuating in Case 
2. Finally, the DC-Link voltage of PMSG and rotor speed profile of SCIG are demonstrated in Figs. 15 and 16. The rotor speed of SCIG is unstable for both Cases as it is disconnected.

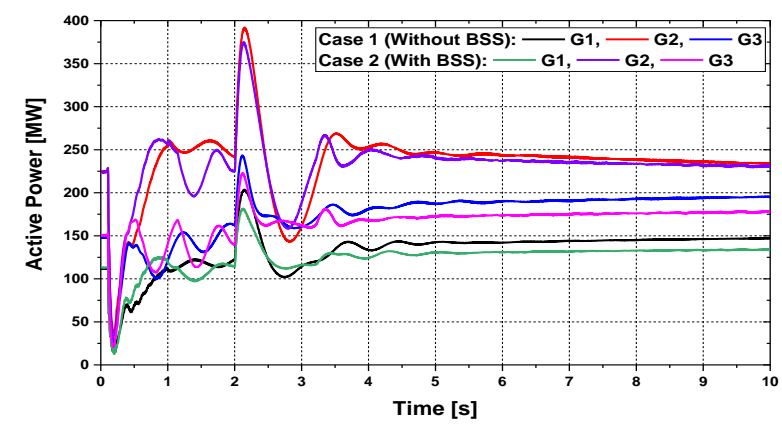

Fig. 9: Active power profiles of SGs.

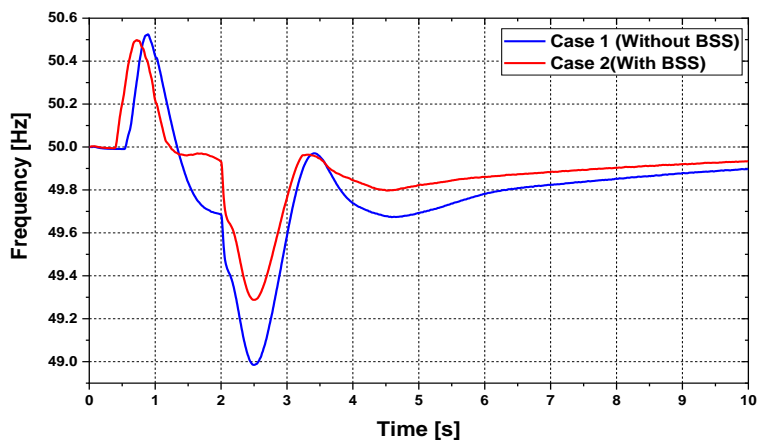

Fig. 10: Frequency profile of power system.

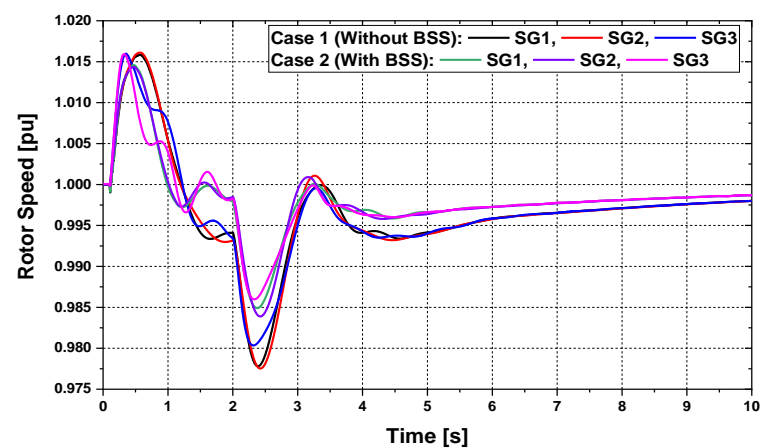

Fig. 11: Rotor speed profiles of SGs.

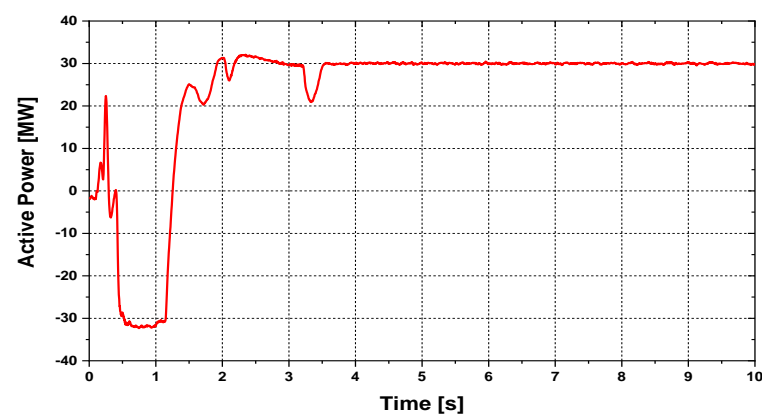

Fig. 12: Active power profile of BSS (Case 2).

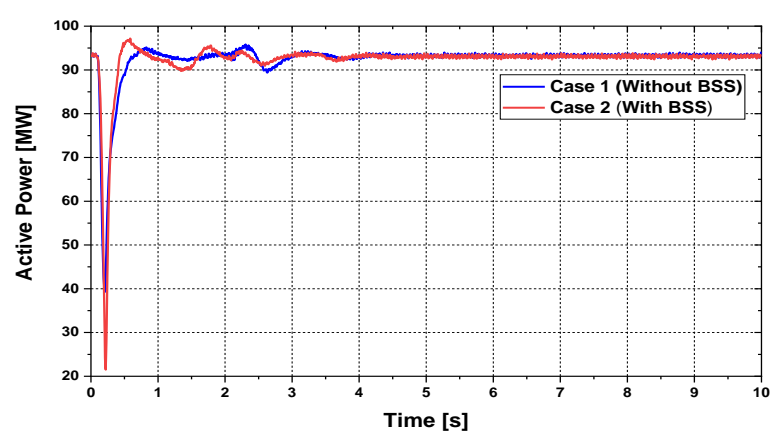

Fig. 13: Active power profile of PMSG.

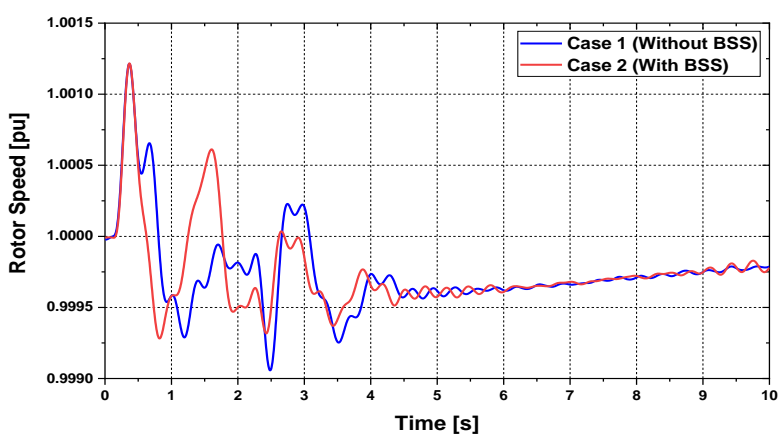

Fig. 14: Rotor speed profile of PMSG.

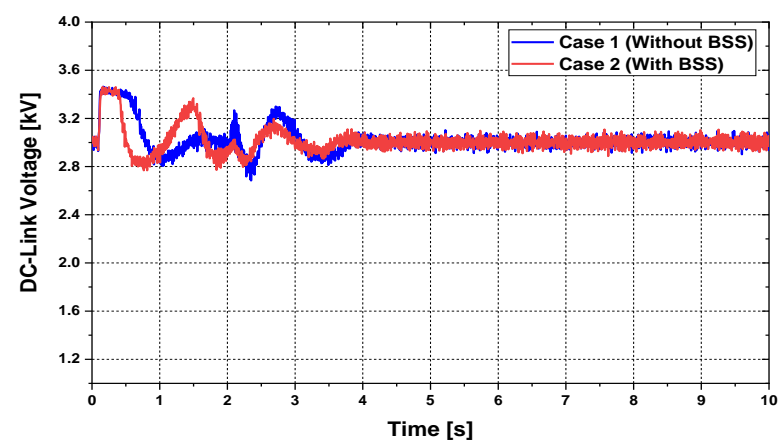

Fig. 15: DC-Link voltage profile of PMSG.

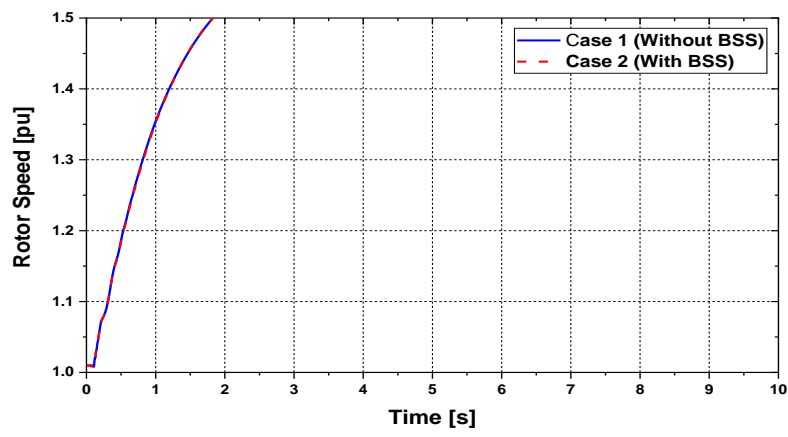

Fig. 16: Rotor speed profile of SCIG.

Based on Fig. 10, the maximum frequency variation in positive axis $(+\Delta f)$, maximum frequency variation in negative axis $(-\Delta f)$ and standard deviation $(\sigma)$ for both cases are calculated which is demonstrated 
in Table 1. The Table 1 confirms that the mentioned parameters variations are less in Case 2. Based on the above detail analysis, it can be concluded that the proposed BSS system have sufficient accuracy to control the frequency nadir after any generation outage because of severe network fault.

Table 1: Parameters of frequency response curve.

\begin{tabular}{|c|c|c|}
\hline & Case 1 (Without BSS) & Case 2 (With BSS) \\
\hline$+\Delta f$ & 0.5249 & 0.4978 \\
\hline$-\Delta f$ & -1.015 & -0.7120 \\
\hline$\sigma$ & 0.1938 & 0.1361 \\
\hline
\end{tabular}

\section{Conclusion}

In this paper, a novel inertial control strategy is developed for BSS to augment the frequency stability of the power system. Detailed design technique of the power system, wind turbine model, SCIG system, PMSG system, BSS as well as its control strategies are adequately demonstrated throughout the paper. Two case studies are also conducted to demonstrate the necessity of the proposed VIC controlled BSS, where 3LG fault is considered to be a severe network fault. Considering all the aspects, the proposed system has encouraging prospective value for minimizing frequency nadir in power system.

\section{References}

[1] Zsiborács, H.; Baranyai, N.H.; Vincze, A.; Zentkó, L.; Birkner, Z.; Máté, K.; Pintér, G. Intermittent Renewable Energy Sources: The Role of Energy Storage in the European Power System of 2040. Electronics 2019, 8, 729.

[2] Ding, X.; Liu, L.; Huang, G.; Xu, Y.; Guo, J. A MultiObjective Optimization Model for a Non-Traditional Energy System in Beijing under Climate Change Conditions. Energies 2019, 12, 1692.

[3] Yap, K.Y.; Sarimuthu, C.R.; Lim, J. .-Y. Virtual InertiaBased Inverters for Mitigating Frequency Instability in GridConnected Renewable Energy System: A Review. Appl. Sci. 2019, 9, 5300.

[4] Pimentel, D.; Herz, M.; Glickstein, M.; Zimmerman, M.; Allen, R.; Becker, K.; Evans, J.; Hussain, B.; Sarsfeld, R.; Grosfeld, A.; et al. Renewable Energy: Current and Potential Issues: Renewable energy technologies could, if developed and implemented, BioScience 2002, 52, 1111-1120.

[5] Global Wind Report 2019, Global Wind Energy Council (GWEC), 2019. Available online: http://www.gwec.net (accessed on 15 June 2020).

[6] Muyeen, S.M.; Tamura, J.; Murata, T. Stability Augmentation of a Grid Connected Wind Farm; Springer: London, UK, 2009.

[7] Hazari, M.R.; Mannan, M.A.; Muyeen, A.; Takahashi, R.; Tamura, J. (2018) Stabilization of Wind Farm by Using PMSG Based Wind Generator Taking Grid Codes into Consideration. Journal of Power and Energy Engineering, 6 , 40-52.
[8] Bevrani, H.; Ghosh, A.; Ledwich, G. Renewable energy sources and frequency regulation: survey and new perspectives. IET Renewable Power Generation 2010, 4, 438-457.

[9] Rakhshani, E.; Rouzbehi, K.; J. Sánchez, A.; Tobar, A.C.; Pouresmaeil, E. Integration of Large Scale PV-Based Generation into Power Systems: A Survey. Energies 2019, $12,1425$.

[10] Shi, R.; Zhang, X. VSG-Based Dynamic Frequency Support Control for Autonomous PV-Diesel Microgrids. Energies 2018, 11, 1814.

[11] Morren, J.; Pierik, J.; Haan, S.W.H. [de Inertial response of variable speed wind turbines. Electric Power Systems Research 2006, 76, 980-987.

[12] Lalor, G.; Mullane, A.; O’Malley, M. Frequency control and wind turbine technologies. IEEE Transactions on Power Systems 2005, 20, 1905-1913.

[13] Vyver, J.V. de; Kooning, J.D.M.D.; Meersman, B.; Vandevelde, L.; Vandoorn, T.L. Droop Control as an Alternative Inertial Response Strategy for the Synthetic Inertia on Wind Turbines. IEEE Transactions on Power Systems 2016, 31, 1129-1138.

[14] Conroy, J.F.; Watson, R. Frequency Response Capability of Full Converter Wind Turbine Generators in Comparison to Conventional Generation. IEEE Transactions on Power Systems 2008, 23, 649-656.

[15] Margaris, I.D.; Papathanassiou, S.A.; Hatziargyriou, N.D.; Hansen, A.D.; Sorensen, P. Frequency Control in Autonomous Power Systems With High Wind Power Penetration. IEEE Transactions on Sustainable Energy 2012, 3, 189-199.

[16] Morren, J.; Haan, S.W.H. de; Kling, W.L.; Ferreira, J.A. Wind turbines emulating inertia and supporting primary frequency control. IEEE Transactions on Power Systems 2006, 21, 433-434.

[17] Hazari, M.R.; Mannan, M.A.; Muyeen, S.M.; Umemura, A.; Takahashi, R.; Tamura, J. Fuzzy Logic based Virtual Inertia Control of DFIG based Wind Generator for Stability Improvement of Hybrid Power System. IEEJ Transactions on Power and Energy 2018, 138, 733-744.

[18] Zhao, J.; Lyu, X.; Fu, Y.; Hu, X.; Li, F. Coordinated Microgrid Frequency Regulation Based on DFIG Variable Coefficient Using Virtual Inertia and Primary Frequency Control. IEEE Transactions on Energy Conversion 2016, 31, 833-845.

[19] Liu, X.; Xu, Z.; Zhao, J. Combined Primary Frequency Control Strategy of Permanent Magnet Synchronous Generator-Based Wind Turbine. Electric Power Components and Systems 2018, 46, 1704-1718.

[20] Li, Y.; Xu, Z.; Wong, K.P. Advanced Control Strategies of PMSG-Based Wind Turbines for System Inertia Support. IEEE Transactions on Power Systems 2017, 32, 3027-3037.

[21] Zeng, X.; Liu, T.; Wang, S.; Dong, Y.; Chen, Z. Comprehensive Coordinated Control Strategy of PMSGBased Wind Turbine for Providing Frequency Regulation Services. IEEE Access 2019, 7, 63944-63953.

[22] Kundur, P. Power System Stability \& Control; McGrawHill Inc.: New York, NY, USA, 1994

[23] Hazari, M.R.; Mannan, M.A.; Muyeen, S.M.; Umemura, A.; Takahashi, R.; Tamura, J. Stability Augmentation of a Grid-Connected Wind Farm by Fuzzy-Logic-Controlled DFIG-Based Wind Turbines. Appl. Sci. 2018, 8, 20.

[24] E. ON NETZ GmbH. Grid Connection Regulation for High and Extra High Voltage; E. ON NETZ GmbH: Essen, Germany, 2006. 
Rima Sultana was born in Dhaka, Bangladesh. She received

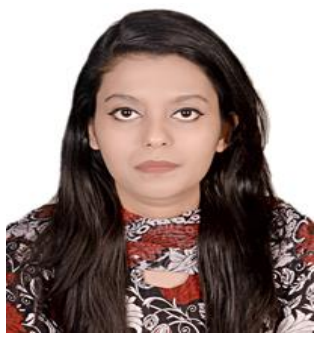
her B.Sc. Engg. Degree in Electrical and Electronic Engineering (EEE) from American International University-Bangladesh (AIUB) in 2018. Currently, she is working towards her master's degree at American International University-Bangladesh (AIUB). Currently, she is working in the science team of AIUB robotic crew. She served as an Intern in demand and cost management technology at Robi Axiata Bangladesh. Her research interests based distinctly on Renewable Energy, Power Electronics, HVDC Systems, Power generation and Smart Grid Systems.

Md. Rifat Hazari received his B.Sc. Engg. and M.Sc. Engg.

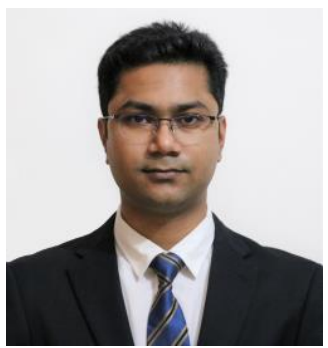
Degrees in Electrical and Electronic Engineering from American International University-Bangladesh (AIUB) in August 2013 and December 2014, respectively and Ph.D. Degree in Energy Engineering from Kitami Institute of Technology (KIT), Japan, in March 2019. He served as a Lecturer in Electrical and Electronic Engineering department at AIUB. Currently, he is working as an Assistant Professor in the Electrical and Electronic Engineering department at AIUB. He received the MINT (Academic Excellence) Award 2017 from KIT for the outstanding research of 2017 academic year, Best Paper Award in the Australasian Universities Power Engineering Conference 2017, Melbourne, Victoria Australia and Best Presentation Award in the IEEJ Branch Convention 2017, Hakodate, Japan. His research interests are renewable energy systems (especially wind power \& photovoltaic power systems), power system stability and control, microgrid and hybrid power systems, HVDC system, analysis and control of rotating electrical machines. Dr. Hazari is a member of IEEE.

Mohammad Abdul Mannan was born in Laxmipur,

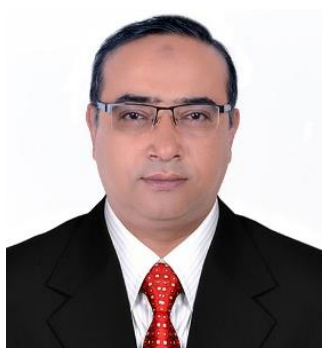
Bangladesh on January 01, 1975 He received his B. Sc. Eng. Degree from Rajshahi University of Engineering and Technology (RUET former BITR), Bangladesh, in 1998, and Masters of Eng. and Dr. of Eng. degrees from Kitami Institute of Technology, Japan, in 2003 and 2006 respectively, all in electrical engineering. He then joined in the American International University Bangladesh (AIUB) as an Assistant professor in May 2006. He served in AIUB as an Associate Professor from December 2013 to November 2016. Now he is working as a Professor and Director of Faculty of Engineering in AIUB. His research interests include electric motor drive, power electronics, power system, wind generation system and control of electric motor, power electronic converters, power system, and wind generation system. Prof. Dr. Mannan is a member of the IEB and IEEE.
Junji Tamura received his B. Sc. Eng. Degree from Muroran

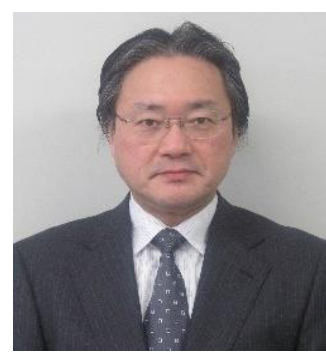
Institute of Technology, Japan, in 1979, and M.Sc. Eng. and Dr. Eng. degrees from Hokkaido University, Japan, in 1981 and 1984 respectively, all in electrical engineering. He became a lecturer in 1984, an Associate Professor in 1986, and a Professor in 1996 at the Kitami Institute of Technology, Japan. From 1991 to 1992, he had joined the Energy Systems Research Center of University of Texas at Arlington (UTA) as a visiting research Professor. He had been a chairman of the committee of Rotating Machinery of IEEJ (The Institute of Electrical Engineers of Japan) from 2008 to 2010, and he was a conference chair of International Conference on Electrical Machines and Systems 2012 (ICEMS 2012, Sapporo, Japan) in 2012. From 2006 to 2014, he had been a Vice President, and from 2014 to 2018 he had been an Executive Vice President of the Kitami Institute of Technology. He is currently a Professor and the Head of the Laboratory of Electric Machinery of the Kitami Institute of Technology, Japan. His main research interests and experience include analysis of synchronous machines, analysis and simulation of power system dynamics and stability, and analysis and control system design of wind power generation system. He has authored or co-authored about 180 peer-reviewed journal papers and presented about 220 papers in international conferences. 